\title{
Multilocus heterozygosity and sexual selection in a natural population of the marine snail Littorina mariae (Gastropoda: Prosobranchia)
}

\author{
EMILIO ROLÁN-ALVAREZ*, CARLOS ZAPATA \& GONZALO ALVAREZ \\ Departamento de Biologia Fundamental (Genética), Facultad de Biología, Universidad de Santiago de Compostela, \\ 15706 Santiago, Spain
}

\begin{abstract}
A positive relationship between heterozygosity and growth rate, or less frequently, between heterozygosity and fitness components, has been found in many species. A particularly important component of net fitness is sexual selection. However, no studies have been made of the relationship between this character and multilocus heterozygosity in natural populations. In this study, a natural population of the intertidal flat periwinkle Littorina mariae was used to investigate the heterozygosity-sexual fitness relationship. A positive heterozygosity-sexual fitness relationship was found in male $L$. mariae, but not in females. The selective coefficients acting on the different heterozygosity classes of males ranged between 0.21 and 0.57 (average 0.39 ), and are similar to those found in previous studies on correlations between heterozygosity and other fitness components. This relationship accounted for approximately 1 per cent of the variance in matings. Furthermore, the contribution of each locus was associated with its homozygosity excess across loci. The positive heterozygosity-sexual fitness relationship showed the same characteristics as the heterozygosity-growth rate correlation. Finally, relationships between sexual selection and size of snail, and heterozygosity and size were found, although they did not account for the heterozygosity-sexual selection relationship.
\end{abstract}

Keywords: associative overdominance hypothesis, fitness estimates, heterosis, mate selection, size.

\section{Introduction}

A positive correlation between allozyme multilocus heterozygosity and different quantitative characters is present in many animal and plant species (Mitton \& Grant, 1984; Zouros \& Foltz, 1987), particularly in marine bivalves (Singh \& Zouros, 1978; Koehn \& Gaffney, 1984; Gaffney et al., 1990; Zouros \& Pogson, 1994). This correlation usually accounts for less than 5 per cent of the variance in growth rate, and is largely influenced by the genetic and demographic structure of the samples, as well as by the experimental or environmental conditions (Zouros, 1987; Zouros \& Foltz, 1987; Gaffney et al., 1990). Moreover, the relationship is usually associated with an excess of homozygosity in the population (Zouros, 1987; Zouros \& Mallet, 1989; Gaffney et al., 1990). On the other hand, the lack of natural occurrence of age cohorts and homozygote excess in many species may commonly impede the detection of correlation (Zouros, 1987).

\footnotetext{
${ }^{*}$ Correspondence.
}

Further examples have been found of correlation with characteristics directly related to fitness, such as viability (Zouros et al., 1983; Diehl \& Koehn, 1985; Alvarez et al., 1989) and fecundity (Linhart \& Mitton, 1985; Rodhouse et al., 1986; Gajardo \& Beadmore, 1989; McAlpine, 1993). The selective coefficients found in most of these studies were as large as 0.47-0.60 (Alvarez et al., 1989). Sexual selection has been suggested as one of the most important single components of net fitness (Endler, 1986). However, we know only one study which reports a multilocus correlation between heterozygosity and sexual selection. In this laboratory study more heterozygous male brine shrimp (Artemia franciscana) were more successful than less heterozygous males during matings; selection coefficients found were similar to those of previous studies (Zapata et al., 1990).

Sexual selection is a term that has been used with many different meanings since Darwin. The present authors adhere to the Darwinian tradition of distinguishing between natural and sexual selection, the latter arising from variance in mating success (Arnold 
\& Wade, 1983a). However, mating success is equated with copulatory success (O'Donald, 1980; Knoppien, 1985; Endler, 1986), which is also consistent with the Darwinian definition (see O'Donald, 1980). The study of sexual selection in nature as a partial component of natural selection can be undertaken by comparing copulating and noncopulating samples for a particular character, i.e. using a cross-sectional design (Arnold \& Wade, 1983b). Thus, if one character is significantly more frequent in copulating than in noncopulating samples, then it may be safely supposed that individuals with that character are more fit during matings. This approach has clear advantages when individual fitness is affected by a particular character at different stages (viability, sexual selection, fecundity, etc.) of the life history of a species (see Prout, 1965; Alvarez et al., 1984).

The aim of this study was to look for evidence of a multilocus heterozygosity-sexual selection relationship in a natural population of a littorinid species with an annual life cycle, Littorina mariae Sacchi \& Rastelli; a directly developed, dioecious and polygamous species from the North Atlantic region (which feeds on microepiphytes of seaweeds). This species has some advantages for this kind of study, as copulating pairs (which remain coupled for 1-2 h) can be found on seaweeds mainly during summer and autumn (Goodwin \& Fish, 1977; Fretter \& Graham, 1980; Rolán-Alvarez, 1992; Williams, 1992; Rolán-Alvarez et al., 1995). In addition, approximate age cohorts can be observed in nature, as crawling juveniles hatch in early spring and grow during summer and autumn. A positive heterozygosity-sexual selection correlation was found in males, but not in females, of the population under study.

\section{Materials and methods}

\section{Sampling procedures, variables and electrophoresis}

Snails were sampled (11-12 July, 1990) during low tides from a rocky semi-exposed shore in the Muros-Noya Ria, Galicia, Spain (see Rolán-Alvarez et $a l ., 1995)$. The two sibling species, $L$. mariae and $L$. obtusata, live sympatrically on Fucus vesiculosus in this area (Rolán-Alvarez, 1992), but they can be distinguished in the laboratory by differences in reproductive characters and by diagnostic allozymic loci (Fretter \& Graham, 1980; Reid, 1990; Zaslavskaya et al., 1992; Rolán-Alvarez et al., 1995).

Two exclusive groups comprising copulating and noncopulating individuals of $L$. mariae were sampled from four contiguous areas (A-D), each covering approximately $150 \mathrm{~m}^{2}$ of $F$. vesiculosus. Pairs of snails were defined as copulating when a male was mounted on another snail and maintained its penis inserted into the partner. Approximately 40 per cent of the pairs found were discarded as the penis was not thoroughly inserted (in mostly male-male or male-juvenile pairings). Noncopulating snails were obtained from a random sample of seaweeds in the same sampling area (excluding the previously discarded unsuccessful pairs).

In $L$. mariae, juveniles have a shell shape and an unthickened part of the growing lip that allow them to be distinguished from the adults (Goodwin \& Fish, 1977; Fretter \& Graham, 1980). In individuals from Galicia, however, these characteristics are not related to sexual maturity, although they can be used as a rough estimate of age, to distinguish young and old snails (Rolán-Alvarez, 1993; Rolán-Alvarez et al., 1995).

All snails were marked, aged according to the characteristics above (young or old snails) and sized (fresh weight and shell height were recorded). Fresh weight was measured by a digital balance $( \pm 0.002 \mathrm{~g})$ and shell height by a manual calliper $( \pm 0.05 \mathrm{~mm})$, following Janson (1982). All snails were stored at $-70^{\circ} \mathrm{C}$ prior to electrophoresis. The sex of all specimens was noted before carrying out electrophoretic analyses for nine polymorphic allozymic loci: phosphogluco-isomerase (EC 5.3.1.9; Pgi), phosphoglucomutase (EC 5.4.2.2; Pgm), mannose-6-phosphate isomerase (EC 5.3.1.8; $\mathrm{Mpi}$ ), esterases (EC 3.1.1.1; Es2 and $E s-c$ ), arginine phosphokinase (EC 2.7.3.3; Ark), aminopeptidase (EC 3.4.13.-; $A p$ ), leucine aminopeptidase (EC 3.4.11.-; Lap-1 and Lap-2). Buffers, staining systems and electrophoresis methods (horizontal starch gel) have been described in detail elsewhere (Rolán-Alvarez, 1993; Rolán-Alvarez et al., 1995). Loci and alleles were labelled in order of decreasing electrophoretic mobility. The number of heterozygous loci of each snail defined the locus and multilocus heterozygosity indexes. Only snails with developed reproductive tracts and genotypes known for the nine loci were used in the analyses.

\section{Statistical analysis}

Variation in allelic frequencies or degree of multilocus heterozygosity between areas, sex or age classes was analysed using $\chi^{2}$ contingency tests. Wright's $F$-statistic $\left(\left(H_{\mathrm{e}}-H_{\mathrm{o}}\right) / H_{\mathrm{e}}\right)$ and $\chi^{2}$ goodness of fit tests were used to study agreement with Hardy-Weinberg expectations. Genotypic associations between pairs of loci were verified by $\chi^{2}$ contingency tests. Pseudoprobability contingency or goodness of fit $\chi^{2}$ tests were employed when low sample sizes within cells $(<5)$ were expected (Zaykin \& Pudovkin, 1993). The sequential Bonferroni 
multitest correction was employed when many tests were carried out simultaneously (Rice, 1989).

Analysis of mating behaviour corresponding to multilocus genotypes was carried out considering the three independent components contributing to mating behaviour: differential male mating success (male sexual selection), differential female mating success (female sexual selection) and mating pattern (Merrell, 1950; Anderson \& McGuire, 1978; Spieth \& Ringo, 1983). A $\chi^{2}$ contingency test was used to study mating pattern (deviation from random mating), and the crossproduct estimator was used to study sexual selection (see Santos et al., 1986; Zapata et al., 1990; Johannesson et al., in press). The latter estimator was used to obtain the relative fitness of multilocus heterozygosity classes with respect to the multilocus homozygosity class, and the relative fitness, for each locus, of heterozygotes with respect to homozygotes. The fitness of a particular heterozygosity class ("1"), relative to the homozygosity class (" 0 ") is defined by the crossproduct estimate given by:

$$
\begin{array}{r}
W \text { “1" }=(\text { Cop " } 1 \text { " } \times \text { Noncop "0") }) \\
\text { (Noncop"1" } \times \text { Cop "0"), }
\end{array}
$$

where Cop is the number of copulating individuals of one sex and Noncop the number of noncopulating individuals of that same sex. Bootstrap fitness estimates were obtained independently for copulating and noncopulating samples from each of 1000 Monte Carlo type resamplings of the data from the two heterozygosity classes for which fitness had previously been estimated. Confidence intervals for each fitness estimate were obtained from the distribution of the 1000 bootstrap fitness estimates. Fitness estimates, variances of estimates, and bootstrap confidence intervals for each fitness estimate were obtained by a (compiled) BASIC program (Rolán-Alvarez, 1993).

Standard parametric and nonparametric tests, on allozyme and quantitative data, were calculated following Sokal \& Rohlf (1981) and Siegel \& Castellan (1988) using the sPSs/PC statistical package.

\section{Results}

\section{Genetic structure of samples}

Allozymic variability and further analyses of genetic structure of noncopulating samples have been described elsewhere (Rolán-Alvarez et al., 1995).

The frequency of sex and age classes, sample size and mean expected heterozygosity for the nine loci analysed are shown, for each $L$. mariae sample, in Table 1. The distributions of sex and age classes were significantly heterogeneous between sampling areas $\left(\chi_{\text {sex }}^{2}=16.5, \quad\right.$ d.f. $=3, \quad P<0.01 ; \quad \chi_{\text {age }}^{2}=12.9, \quad$ d.f. $=3$, $P<0.01)$. Nevertheless, there was no significant allelic heterogeneity at single loci after Bonferroni corrections, between areas or between sex or age classes within areas, for copulating or noncopulating samples. Moreover, frequencies of heterozygosity classes (individuals grouped by a particular heterozygosity index) were homogeneous, between areas or between sex or age classes within areas, after Bonferroni corrections for copulating or noncopulating samples. These results allowed pooling of all areas, within copulating and noncopulating groups, for statistical tests related to the locus or multilocus heterozygosity indices.

Most loci showed $F$-values close to HardyWeinberg expectations in copulating and noncopulating samples of $L$. mariae, but significant hetero-

Table 1 Percentage of male, female, young and old snails in the four areas of copulating and noncopulating Littorina mariae

\begin{tabular}{|c|c|c|c|c|c|c|c|c|c|c|}
\hline \multirow{2}{*}{$\begin{array}{l}\text { Sampled } \\
\text { area }\end{array}$} & \multicolumn{6}{|c|}{ Noncopulating } & \multicolumn{4}{|c|}{ Copulating } \\
\hline & $N$ & Males & Females & Young & Old & $H_{\mathrm{e}}$ & $\mathrm{N}$ & Young & Old & $H_{\mathrm{e}}$ \\
\hline A & 121 & 28.9 & 71.1 & 63.7 & 36.3 & $\begin{array}{c}0.150 \\
(0.048)\end{array}$ & 134 & 61.7 & 38.3 & $\begin{array}{c}0.141 \\
(0.047)\end{array}$ \\
\hline B & 100 & 48.0 & 52.0 & 66.0 & 34.0 & $\begin{array}{c}0.136 \\
(0.044)\end{array}$ & 97 & 56.7 & 43.3 & $\begin{array}{c}0.149 \\
(0.045)\end{array}$ \\
\hline $\mathrm{C}$ & 68 & 57.4 & 42.6 & 41.4 & 58.6 & $\begin{array}{c}0.148 \\
(0.047)\end{array}$ & 72 & 61.1 & 38.9 & $\begin{array}{c}0.159 \\
(0.050)\end{array}$ \\
\hline D & 136 & 42.6 & 57.4 & 62.9 & 37.1 & $\begin{array}{c}0.157 \\
(0.059)\end{array}$ & 144 & 73.6 & 26.4 & $\begin{array}{c}0.141 \\
(0.054)\end{array}$ \\
\hline Total & 425 & & & & & & 447 & & & \\
\hline
\end{tabular}
samples

$H_{\mathrm{e}}$ is the unbiased heterozygosity estimate $(\mathrm{Nei}, 1978)$ for the nine studied loci (standard errors in parentheses). $N$ is the sample size. 
zygote deficiencies were observed in 11 cases (from 65 tests). However, only Lap-1 in area D, for copulating samples, showed a significant and positive $F$-value after Bonferroni corrections $(P<0.05)$.

All pairs of loci were tested for genotypic associations. No significant associations were observed after Bonferroni corrections.

\section{Heterozygosity-sexual selection correlation}

Genotypes for allozymic loci and multilocus heterozygosity classes were randomly distributed between mating pair combinations for the pooled areas $\left(\chi_{9}^{2}=5.1, P=0.825\right)$. Thus, mating was not assortative for these genotypes.

The association between sexual selection (giving to noncopulating snails a value of 0 and to copulating ones a value of 1) and individual heterozygosity was positive and significant for total pooled males, but not for total pooled females (see $\tau$ estimates in Table 2). Similarly, copulating males showed larger heterozygosity ranks than noncopulating ones in total males $\left(U=17601, n_{1}=180, n_{2}=227, P=0.012\right)$ and in young males $\left(U=7287, \quad n_{1}=106, \quad n_{2}=161\right.$, $P<0.037)$, but not in old males $\left(U=1858, n_{1}=65\right.$, $\left.n_{2}=66, P=0.166\right)$. However, no such trend was found in females: total $\left(U=26489, n_{1}=246, n_{2}=220\right.$, $P=0.681)$, young $\left(U=8015, n_{1}=135, n_{2}=126\right.$, $P=0.399)$, old females $\left(U=4870, n_{1}=105, n_{2}=94\right.$, $P=0.868$ ).

Sexual fitness for multilocus heterozygosity classes, for both sexes and all samples, is shown in Table 2 . Fitness for multilocus heterozygosity classes tended to be larger in males than in females, in every area (except area C) and in the pooled areas. Sexual fitness was significant in some male heterozygosity classes after bootstrapping: in all heterozygosity classes from area $\mathrm{D}$ and in 2-3 heterozygosity classes from the pooled samples (Table 2). Only males from areas A and D had a significant sexual fitness (1-3 multilocus heterozygosity classes). The sexual fitness values for each heterozygosity class can be converted to selection coefficients, the less fit heterozygosity classes relative to the most fit one, thus facilitating comparison with other experiments. Total pooled male heterozygosity classes showed an average selection coefficient of 0.39 (range 0.21-0.57), while in area D estimates of selection coefficients ranged from 0.14 to 0.76 with an average of 0.43 . In addition, sexual fitness tended to be more heterogeneous among areas in males than in females (Table 2).

Table 2 Sexual fitness estimates for heterozygosity classes for male and female Littorina mariae from the four areas and all areas pooled

\begin{tabular}{|c|c|c|c|c|c|c|c|c|c|c|c|c|}
\hline & \multicolumn{5}{|c|}{ Males } & & \multicolumn{5}{|c|}{ Females } & \\
\hline & \multicolumn{4}{|c|}{ Multilocus heterozygosity } & \multirow[b]{2}{*}{ Mean } & & \multicolumn{4}{|c|}{ Multilocus heterozygosity } & \multirow[b]{2}{*}{ Mean } & \\
\hline & 0 & 1 & 2 & $3-5$ & & & 0 & 1 & 2 & $3-5$ & & \\
\hline $\mathrm{A}$ & 1.00 & $\begin{array}{c}1.57 \\
(0.87)\end{array}$ & $\begin{array}{c}2.18 \\
(1.27)\end{array}$ & $\begin{array}{c}1.83 \\
(1.57)\end{array}$ & $\begin{array}{c}1.86^{*} \\
(0.18)\end{array}$ & & 1.00 & $\begin{array}{c}0.96 \\
(0.41)\end{array}$ & $\begin{array}{c}1.70 \\
(0.84)\end{array}$ & $\begin{array}{c}0.95 \\
(0.58)\end{array}$ & $\begin{array}{c}1.20 \\
(0.25)\end{array}$ & \\
\hline B & 1.00 & $\begin{array}{c}1.10 \\
(0.59)\end{array}$ & $\begin{array}{c}1.25 \\
(0.70)\end{array}$ & $\begin{array}{c}2.92 \\
(2.94)\end{array}$ & $\begin{array}{c}1.76 \\
(0.58)\end{array}$ & & 1.00 & $\begin{array}{c}1.62 \\
(0.97)\end{array}$ & $\begin{array}{c}0.70 \\
(0.46)\end{array}$ & $\begin{array}{l}1.25 \\
(0.88)\end{array}$ & $\begin{array}{c}1.19 \\
(0.27)\end{array}$ & \\
\hline $\mathrm{C}$ & 1.00 & $\begin{array}{c}0.79 \\
(0.48)\end{array}$ & $\begin{array}{c}0.90 \\
(0.58)\end{array}$ & $\begin{array}{c}0.45 \\
(0.69)\end{array}$ & $\begin{array}{c}0.71 \\
(0.14)\end{array}$ & & 1.00 & $\begin{array}{c}1.97 \\
(1.39)\end{array}$ & $\begin{array}{c}0.44 \\
(0.35)\end{array}$ & $\begin{array}{c}0.66 \\
(0.67)\end{array}$ & $\begin{array}{c}1.02 \\
(0.48)\end{array}$ & \\
\hline $\mathrm{D}$ & 1.00 & $\begin{array}{c}2.51^{*} \\
(1.22)\end{array}$ & $\begin{array}{c}3.59^{*} \\
(2.12)\end{array}$ & $\begin{array}{c}4.18^{*} \\
(2.93)\end{array}$ & $\begin{array}{c}3.43^{*} \\
(0.49)\end{array}$ & & 1.00 & $\begin{array}{c}1.22 \\
(0.50)\end{array}$ & $\begin{array}{c}1.09 \\
(0.48)\end{array}$ & $\begin{array}{c}0.41 \\
(0.32)\end{array}$ & $\begin{array}{c}0.90 \\
(0.25)\end{array}$ & \\
\hline Mean & & $\begin{array}{c}1.49 \\
(0.37)\end{array}$ & $\begin{array}{c}1.98 \\
(0.60)\end{array}$ & $\begin{array}{c}2.34 \\
(0.79)\end{array}$ & & & & $\begin{array}{c}1.44 \\
(0.22)\end{array}$ & $\begin{array}{c}0.98 \\
(0.27)\end{array}$ & $\begin{array}{c}0.82 \\
(0.18)\end{array}$ & & \\
\hline $\begin{array}{l}\text { Pooled } \\
(A+B+C+D)\end{array}$ & 1.00 & $\begin{array}{c}1.43 \\
(0.37)\end{array}$ & $\begin{array}{c}1.81^{*} \\
(0.51)\end{array}$ & $\begin{array}{l}2.30^{*} \\
(0.96)\end{array}$ & $\begin{array}{c}1.85 \\
(0.25)\end{array}$ & & 1.00 & $\begin{array}{c}1.27 \\
(0.30\rangle\end{array}$ & $\begin{array}{c}1.00 \\
(0.27)\end{array}$ & $\begin{array}{c}0.83 \\
(0.28)\end{array}$ & $\begin{array}{c}1.03 \\
(0.13)\end{array}$ & \\
\hline & & & & & & $\begin{array}{c}\tau=0.12^{*} \\
407\end{array}$ & & & & & & $\begin{array}{c}\tau=-0.02 \\
465\end{array}$ \\
\hline
\end{tabular}

${ }^{*} P<0.05$.

Theoretical errors of the fitness values are shown in parentheses (Alvarez et al., 1989). Fitness estimates of heterozygosity classes were compared statistically with the homozygosity class by bootstrapping (see text). Kendall's tau association test $(\tau)$ between sexual selection and individual heterozygosity, and sample size used, are presented for pooled samples of males and females. 
The same trend for the sexual fitness estimates was observed in young and old males and females. Selection coefficients in young males ranged between 0.37 and 0.65 , with an average of 0.49 , while in young females the range was between 0.01 and 0.25 , with an average of 0.14 . Selection coefficients in old males ranged between 0.19 and 0.47 (average 0.37 ), while in old females the range was between 0.13 and 0.5 (average 0.33). There were no significant fitness estimates in males or females within age classes when bootstrapping was used, perhaps because of the low sample sizes of the estimates. However, the relationship between sexual fitness and heterozygosity classes could be shown by Kendall's tau association test: total males $(\tau=0.34, n=16, P<0.10)$, young males $(\tau=0.44, n=15, P<0.05)$, old males $(\tau=0.10$, $n=15$, NS), total females $(\tau=-0.23, n=16$, NS), young females $(\tau=-0.13, n=16, \mathrm{NS})$ and old females $(\tau=-0.24, n=16$, NS). Males, but no females, showed a positive association between multilocus hetero- zygosity classes and their fitness values. This trend was especially obvious in young snails (Fig. 1).

The contribution of each locus to the multilocus heterozygosity-sexual selection correlation was found by means of the fitness of pooled heterozygotes relative to pooled homozygotes for each locus. Heterozygotes from Lap-1 showed the largest mating advantage, although by the conservative Bonferroni approach it was not significant. The loci which contributed the most to the multilocus heterozygosity-sexual selection correlation were those $\mathrm{m}$ which we found more homozygotes in the population than expected from Hardy-Weinberg $(\tau=0.46, n=25, P<0.01)$. Again, no such trend was observed in females $(\tau=0.18$, $n=27, \mathrm{NS}$ ) (Fig. 2).

Zouros (1993) proposed a test to evaluate the associative overdominance hypothesis. According to this hypothesis a positive correlation is expected between the degree of unbiased heterozygosity ( $\mathrm{Nei}$, 1978) and the contribution of each locus (see above)
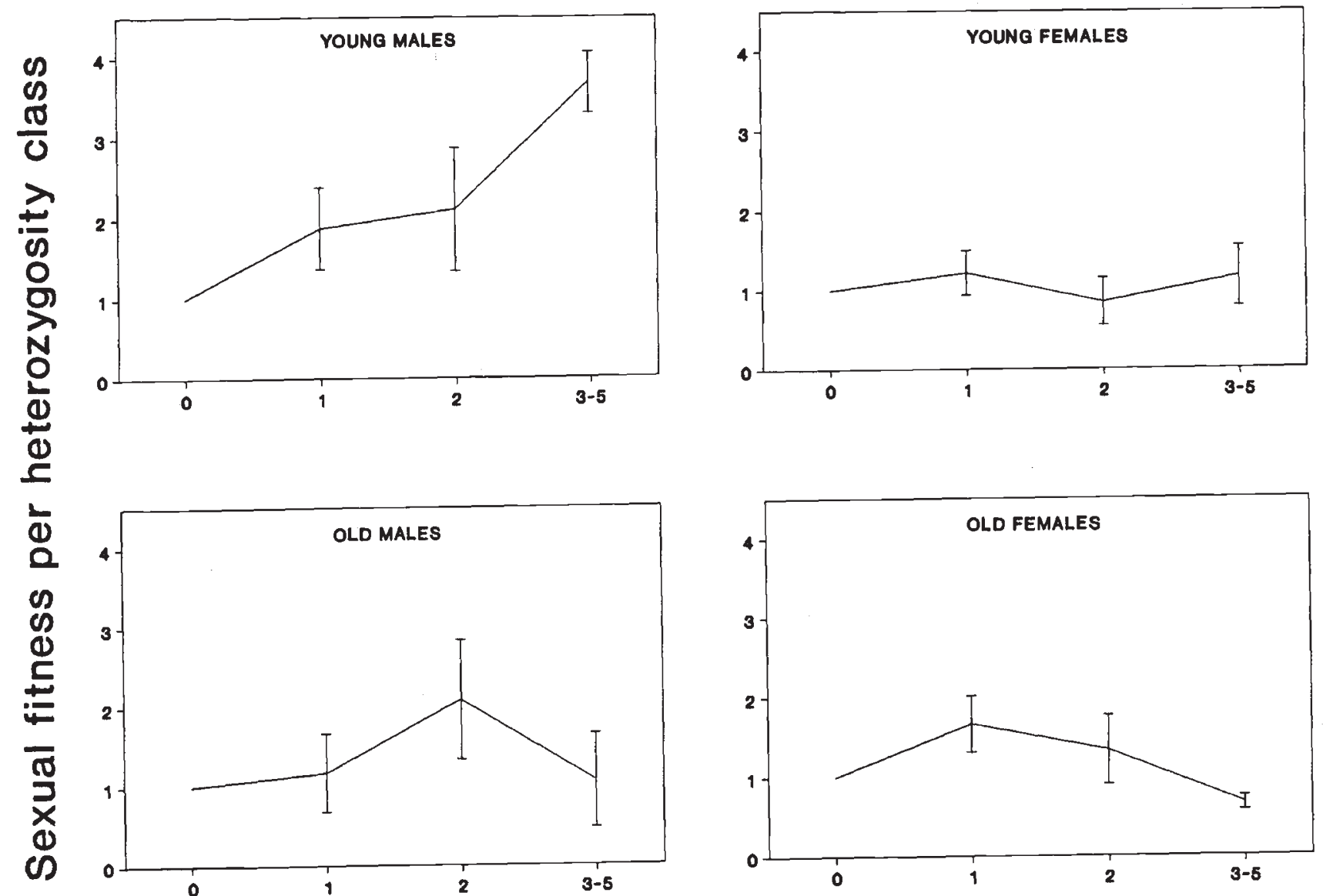

\section{Heterozygous loci per snail}

Fig. 1. The heterozygosity-sexual selection relationship in young and old, male and female Littorina mariae. Average sexual fitnesses in sampling areas are shown for all heterozygosity classes (relative to the homozygosity class). Vertical segments are standard errors. 


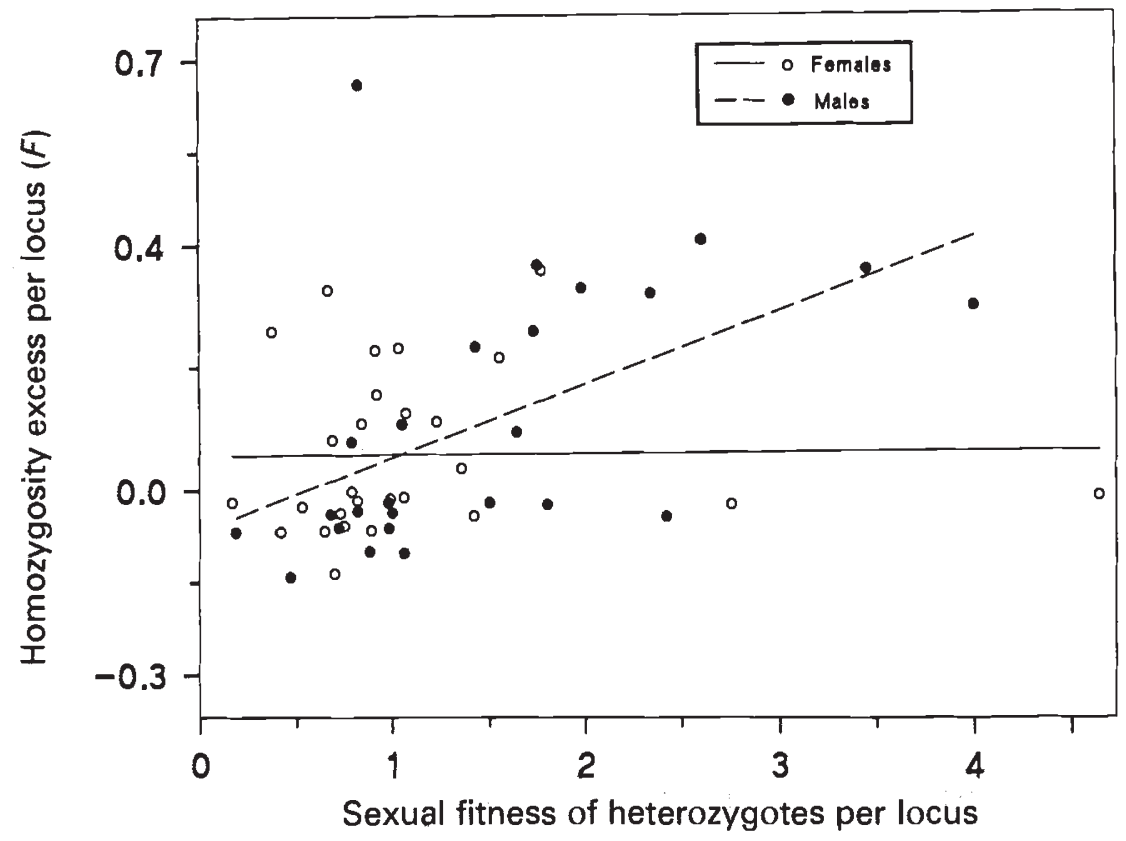

Fig. 2. The homozygosity-sexual selection relationship for male and female Littorina mariae from pooled samples. The relationship between sexual fitness of heterozygotes, and the homozygosity excess $(f)$ of noncopulating samples is shown for every locus and area. The regression line for each sex is also presented.

across the studied loci. We have carried out this test for males and females of the studied population. The results failed to support the associative overdominance hypothesis. No correlation between heterozygosity and the contribution of each locus across loci was found in males $(r=0.305, n=9, P=0.424)$ or in females $(r=-0.279, n=9, P=0.467)$. However, this test does not allow us to differentiate between distinct rival hypotheses (see Zouros, 1993).

\section{Heterozygosity-size relationship}

Total fresh weight and shell height were highly correlated in snails $(r=0.892, n=861, P<0.001)$, and they represent different size estimates. The mean size (weight) of males and females in different heterozygosity classes, within copulating and noncopulating samples, is shown graphically in Fig. 3. The shell height is not represented as it showed the same pattern as the weight. Sizes were not significantly different among heterozygosity classes, within copulating and noncopulating groups, in males or in females (Fig. 3). However, copulating males showed a significant negative correlation between multilocus heterozygosity and weight of each snail $(r=-0.142, n=227, P<0.05)$, although there was a nonsignificant correlation with shell height $(r=-0.131, \quad n=218, \quad P<0.10)$. Nevertheless, no significant correlations between size and individual heterozygosity were observed in males and females from the noncopulating or the pooled samples (copulating and noncopulating). Furthermore, a negative association between size and sexual selection (giving 0 for noncopulating and 1 for copulating) was observed in males $\left(r_{\text {weight }}=-0.144, \quad n=397, \quad P<0.01\right.$;
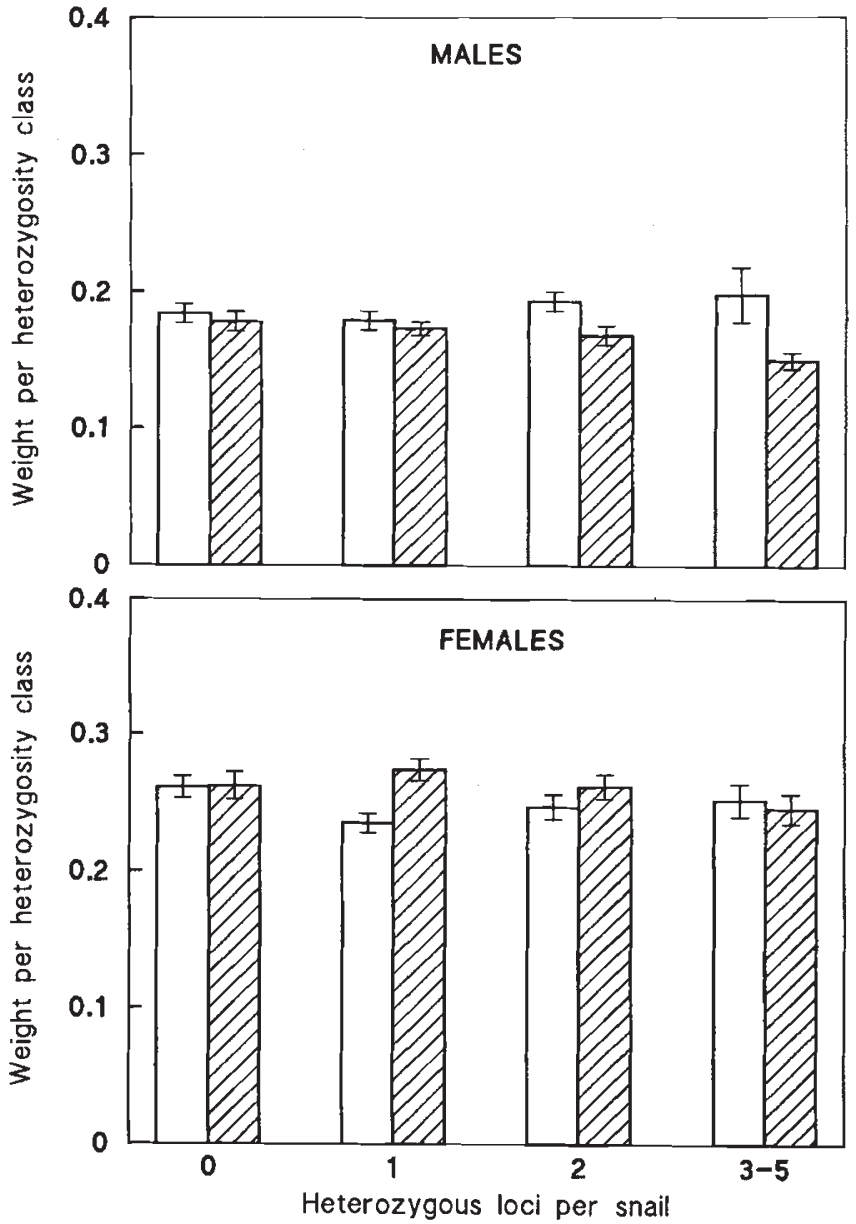

Fig. 3. The average fresh weights and standard deviations (g) are shown for male and female heterozygosity classes in copulating and noncopulating samples of Littorina mariae. Open bars represent noncopulating samples and hatched bars copulating ones. 
$\left.r_{\text {height }}=-0.165, n=388, P<0.001\right)$, while a positive association was found in females $\left(r_{\text {weight }}=0.131\right.$, $\left.n=459, P<0.01 ; r_{\text {height }}=0.123, n=453, P<0.01\right)$. In other words, small males and large females mated most often.

\section{Discussion}

Sexual fitness was positively associated with multilocus heterozygosity in male L. mariae (Galicia: NW Spain). However, this relationship was absent in female $L$. mariae from the same samples. Males and females are expected to contribute differently to mating behaviour (O'Donald, 1980; Spieth \& Ringo, 1983), and distinct mating components between sexes have already been described for littorinids in nature (e.g. L. saxatilis: Johannesson et al., in press). In $L$. mariae, the life history characteristics suggest that it may represent a typical polygamous species with a larger potential for sexual selection in males than in females (RolánAlvarez, 1993). It may be that females invest their energy in other fitness components (Rodhouse et al., 1986; Zouros \& Foltz, 1987).

Male L. mariae showed an increase in sexual fitness with the degree of multilocus heterozygosity. In fact, sexual fitness in males was impressive for some multilocus heterozygosity classes. The average selection coefficients for heterozygosity classes in total males were as high as 0.39 (range $0.21-0.57$ ), as large as the selection coefficients observed in the study on multilocus heterozygosity and sexual selection in Artemia franciscana (Zapata et al., 1990) or the studies on heterozygosity and viability in marine bivalves (see Alvarez et al., 1989). However, these impressive selection coefficients were observed in a relationship that only explained 1 per cent of the variance in matings. The low percentage of variance explained by the multilocus heterozygosity seems to be contradictory to the large selection coefficients found in heterozygosity classes, but this is not so. The fitness estimates were obtained from grouped individuals (amplifying the effects of the relationship - see below), while the percentage of variance explained was obtained from the association between individual heterozygosity and sexual selection (see $\tau$ estimates in Table 2). Similarly, amplifying effects of hierarchical averages have already been described for the heterozygosity-growth rate relationship (Zouros, 1987): when individuals with the same number of heterozygous loci are placed in the same group, the pooling will amplify the correlation between heterozygosity and phenotypic score. Moreover, Zouros (1987) noted at least four different nested levels contributing to the amplifying average effects of heterosis.
The heterozygosity-sexual fitness correlation was age-dependent, being significant only in young snails. This relationship only explained a small percentage of the variance ( 1 per cent) in the character studied (matings), and showed considerable heterogeneity among samples (Table 1 and mean errors in Fig. 1). In addition, the contribution of each locus to the multilocus association was related to the homozygosity excess of the locus in the sample (Fig. 2). Such associations are typically found in populations with heterozygosity-growth rate correlations (see Mitton \& Grant, 1984; Zouros, 1987; Zouros \& Foltz, 1987; Zouros \& Mallet, 1989; Zouros \& Pogson, 1994).

There are many possible explanations for heterozygosity-phenotypic trait correlations (reviewed in: Zouros, 1987; Zouros \& Foltz, 1987; Zouros \& Mallet, 1989; Gaffney et al., 1990). The characteristics of allozyme heterozygosity-quantitative trait correlations have been claimed to support the associative overdominance hypothesis (Zouros, 1987; Zouros \& Mallet, 1989; but see Koehn, 1990). However, a comparison between allozyme and RFLP heterozygosities provides evidence against it (Pogson \& Zouros, 1994). Zouros (1987, 1993) suggested some tests to verify the associative overdominance hypothesis. However, we could only use one of these with our data because the loci employed were mostly diallelic and paired linkage relationships were not observed in similar littorinid species (Ward et al., 1986, 1991). The associative overdominance hypothesis was not supported by our data, although the results must be considered as preliminary because of the low number of loci employed. In fact, no conclusive evidence exists for any of the hypotheses described to explain the heterosis with the allozyme markers.

The heterozygosity-sexual fitness relationship appears to be associated with mating-size and heterozygosity-size relationships in $L$. mariae. Small males and large females were most successful during matings. In other littorinid species large males are at an advantage in conquering and retaining females during matings (see Johannesson et al., in press). Male and female mating-size correlations are very similar in magnitude, suggesting that a factor other than the heterozygosity-sexual fitness relationship (which only affected males) causes the former correlation. A significant negative correlation between heterozygosity and size is found in copulating males, but is absent in copulating females, in noncopulating and in pooled (copulating and noncopulating) males and females. Moreover, the significant heterozygosity-size correlation of male $L$. mariae did not show the usual relationship of size being positively associated with heterozygosity (Mitton \& Grant, 1984; Zouros \& 
Foltz, 1987). These relationships probably suggest that young males invest most of their energy in sexual activities, which also affect negatively their growth rate.

A positive relationship between sexual fitness and individual heterozygosity has been observed in male $L$. mariae. Moreover, this relationship had the same characteristics as the known heterozygosity-growth rate correlation. Relationships between size and fitness in males and females and between heterozygosity and size in copulating males were observed. In fact, these phenomena in young males may represent related effects from a natural life history-heterozygosity relationship. The evolutionary significance of the correlation between allozyme heterozygosity and quantitative traits is not clear (Pogson \& Zouros, 1994). In fact, the degree of the relationship between heterozygosity and sexual selection in $L$. mariae was different among individuals from that of individuals grouped according to their heterozygosity level, which may suggest the existence of some bias contributing to the phenomenon. Moreover, the correlation has previously been explained in terms of dominance variance (heterosis) (Zouros \& Foltz, 1987), but also in terms of additive variance (Chackraborty, 1987). Nevertheless, selection on a polygenic trait is able to change gene frequencies (affecting the trait) mainly by the additive variance component (Falconer, 1981).

\section{Acknowledgements}

One of us (E. R.-A.) thanks D. Mayo and H. Quesada for help during sampling, H. Quesada and C. Saavedra for general discussions of $\mathrm{K}$. Johannesson and two anonymous referees for improving a version of the manuscript. Philip Mason improved the English of a later version. E. R.-A. was suported by a fellowship from the XUNTA DE GALICIA and the University of Santiago.

\section{References}

AlvareZ, G., ZapaTA, C., AMARO, R. AND GUerra, A. 1989. Multilocus heterozygosity and fitness in the European oyster, Ostrea edulis L. Heredity, 63, 359-372.

AlvareZ, G., SANTOS, M. AND ZAPATA, c. 1984. Frequencydependent selection arising from inappropriate fitness estimation. Evolution, 38, 696-699.

ANDERSON, W. W. AND McGUiRE, P. R. 1978. Mating pattern and mating success of Drosophila pseudoobscura karyotypes in large experimental populations. Evolution, 32, 416-423.

ARNOLD, S. J. AND WADE, M. J. 1983a. On the measurement of natural and sexual selection: theory. Evolution, 38, 709-719.
ARNOLD, S. J. AND WADE, M. J. 1983b. On the measurement of natural and sexual selection: applications. Evolution, 38, 720-734.

CHAKRABORTY, R. 1987. Biochemical heterozygosity and phenotypic variability of polygenic traits. Heredity, $\mathbf{5 9}$, 19-28.

DIEHL, W. J. AND KOEHN, R. K. 1985. Multiple locus heterozygosity, mortality, and growth in a cohort of Mytilus edulis. Mar. Biol., 88, 265-271.

ENdler, J. A. 1986. Natural Selection in the Wild. Princeton University Press, Princeton, NJ.

FALCONER, D. S. 1981. Introduction to Quantitative Genetics, 2nd edn. Longman, London.

FRETTER, V. AND GRAHAM, A. 1980. The prosobranch molluscs of Britain and Denmark. Part 5. Marine Littorinaceae. J. Moll. Stud., Suppl. 7, 243-284.

GAFFNEY, P. M., SCOTT, T. M., KOEHN, R. K. AND DIEHL, W. J. 1990. Interrelationships of heterozygosity, growth rate and heterozygote deficiencies in the coot clam, Mulinia lateralis. Genetics, 124, 687-699.

GAJARDo, G. M. AND BEARDMORE, J. A. 1989. Ability to switch reproductive mode in Artemia is related to maternal heterozygosity. Mar. Ecol. Prog. Ser., 55, 191-195.

GOODWIN, B. J. AND FISH, J. D. 1977 . Inter and intra specific variation in L. obtusata and L. mariae. J. Moll. Stud., 43, 241-254.

JANSON, K. 1982. Genetic and environmental effects on the growth rate of Littorina saxatilis Olivi. Mar. Biol., 69, 73-78.

JOHANNESSON, K., ROLAN-ALVAREZ, E. AND EKENDAHL, A. (in press). Incipient reproductive isolation between two sympatric morphs of the intertidal snail Littorina saxatilis. Evolution.

KNOPPIEN, P. 1985. Rare male mating advantage: a review. Biol. Rev., 60, 81-117.

KOEHN, R. K. 1990. Heterozygosity and growth in marine bivalves, comments on the paper by Zouros, RomeroDorey and Mallet (1988). Evolution, 44, 213-216.

KOEHN, R. K. AND GAFFNEY, P. M. 1984. Genetic heterozygosity and growth rate in Mytilus edulis. Mar. Biol., 82, 1-7.

LINHART, Y. B. AND MITTON, J. B. 1985. Relationships among reproduction, growth rates, and protein heterozygosity in Ponderosa pine. Am. J. Bot., 72, 181-184.

McAlPINE, s. 1993. Genetic heterozygosity and reproductive success in the green treefrog, Hyla cinerea. Heredity, 70, 553-558.

MERRELL, D. J. 1950. Measurement of sexual isolation and selective mating. Evolution, 4, 326-331.

MITTON, J. B. AND GRANT, M. c. 1984. Associations among protein heterozygosity, growth rate, and developmental homeostasis. Ann. Rev. Ecol. Syst., 15, 479-499.

NEI, M. 1978. Estimation of average heterozygosity and genetic distance from a small number of individuals. Genetics, 89, 583-590.

o'DONAld, P. 1980. Genetic Models of Sexual Selection. Cambridge University Press, London.

POGSON, G. H. AND zouros, E. 1994. Allozyme and RFLP heterozygosities as correlates of growth rate in the scallop Placopecten magellanicus, a test of the associative overdominance hypothesis. Genetics, 137, 221-231. 
PROUT, T. 1965. The estimation of fitnesses from genotypic frequencies. Evolution, 19, 546-551.

REID, D. G. 1990. Note on the discrimination of females of Littorina mariae Sacchi and Rastelli and L. obtusata (Linnaeus). J. Moll. Stud., 56, 113-114.

RICE, W. R. 1989. Analyzing tables of statistical tests. Evolution, 43, 223-225.

RODHOUSE, P. G., McDONALD, J. H., NEWELL, R. I. E. AND KOEHN, R. K. 1986. Gamete production, somatic growth and multiplelocus enzyme heterozygosity in Mytilus edulis. Mar. Biol., 90, 209-214.

ROLAN-AlvAREZ, E. 1992. A method of breeding Littorina obtusata (L.) and L. mariae Sacchi and Rastelli: preliminary results. In: Grahame, J., Mill, P. J. and Reid, D. G. (eds) Proceedings of the Third International Symposium on Littorinid Biology, pp. 163-167. The Malacological Society of London, London.

ROLAN-Alvarez, E. 1993. Estructura Genética y Selección Sexual en Poblaciones Naturales de dos Especies Gemelas del Género Littorina. Ph.D. Thesis, Universidad de Santiago de Compostela.

RolÁN-AlvareZ, E., ZAPATA, C. AND ALVAreZ, G. 1995. Distinct genetic subdivision in sympatric and sibling species of the genus Littorina (Gastropoda: Littorinidae). Heredity, 74, 1-9.

SANTOS, M., TARRIO, R., ZAPATA, C. AND ALVAREZ, G. 1990. Sexual selection on chromosomal polymorphism in Drosophila subobscura. Heredity, 57, 161-169.

SIEGEL, S. AND CASTELlAN, N. J. 1988. Non-parametric Statistics for the Behavioral Sciences. McGraw-Hill, New York.

SINGH, S. M. AND Zouros, E. 1978. Genetic variation associated with growth rate in the American oyster (Crassostrea virginica). Evolution, 32, 342-353.

SOKAL, R. R. AND ROHLF, F. J. 1981. Biometry, 2nd edn. W. H. Freeman, San Francisco.

SPIETH, H. T. AND RINGO, J. M.. 1983. Mating behavior and sexual isolation in Drosophila. In: Ashburner, M., Carson, H. L. and Thompson, J. N., Jr (eds) The Genetics and Biology of Drosophila, vol. 3c, pp. 223-284. Academic Press, London.
WARD, R. D., WARWICK, T. AND KNIGHT, A. J. 1986. Genetic analysis of ten polymorphic enzyme loci in Littorina saxatilis (Prosobranchia, Mollusca). Heredity, 57, 223-241.

WARD, R. D., WARWICK, T. AND KNIGHT, A. J. 1991. Further genetic analysis of polymorphic enzyme loci in Littorina saxatilis (Prosobranchia, Mollusca). Heredity, 66, 151-158.

WILliams, G. A. 1992. The effect of predation on the life histories of Littorina obtusata and L. mariae. J. Mar. Biol. Ass. U.K., 72, 403-416.

ZAPATA, C., GAJARDO, G. AND BEARDMORE, J. A. 1990. Multilocus heterozygosity and sexual selection in the brine shrimp Artemia franciscana. Mar. Ecol. Prog. Ser., 62, 211-217.

ZASLAVSKAYA, N. I., SERGIEVSKY, S. O. AND TATARENKOV, A. N. 1992. Allozyme similarity of Atlantic and Pacific species of Littorina (Gastropoda, Littorinidae). J. Moll. Stud., 58, 377-384.

ZAYKIN, D. V. AND PUDOVKIN, A. I. 1993. Two programs to estimate significance of $\chi^{2}$ values using pseudo-probability tests. J. Hered., 84, 152.

zoURos, E. 1987. On the relation between heterozygosity and heterosis, an evaluation of evidence from marine mollusks. Isozymes Curr. Top. Biol. Med. Res., 15, 255-270.

zouRos, E. 1993. Associative overdominance: evaluating the effects of inbreeding and linkage disequilibrium. Genetica, 89, 35-46.

Zouros, E. AND FOLTZ, D. w. 1987. The use of allelic isozyme variation for the study of heterosis. Isozymes Curr. Top. Biol. Med. Res., 13, 1-59.

zoURos, E. AND MALLET, A. L. 1989. Genetic explanations of the growth/heterozygosity correlation in marine mollusks. In: Ryland, J. S. and Tyler, P. A. (eds) Reproduction, Genetics and Distributions of Marine Organisms, pp. 317-324. Olsen and Olsen, Fredensborg, Denmark.

zoUROS, E. AND POGSON, G. H. 1994. The present status of the relationship between heterozygosity and heterosis. In: Beaumont, A. R. (ed.) Genetics and Evolution of Aquatic Organisms, pp. 135-146. Chapman and Hall, London.

ZouRos, E., SINGH, S. M., FOLTZ, D. W. AND MALLET, A. L. 1983. Postsettlement viability in the American oyster (Crassostrea virginica): an overdominant phenotype. Genet. Res., 41, 259-270. 